OPEN ACCESS

Edited by:

Katja Witzel,

Leibniz Institute of Vegetable and Ornamental Crops, Germany

Reviewed by:

Salah Elsayed Mohamed Elsayed,

University of Sadat City, Egypt

Shawn Carlisle Kefauver,

University of Barcelona, Spain

Werner B. Herppich,

Leibniz Institute for Agricultural

Engineering and Bioeconomy (ATB),

Germany

*Correspondence:

Yilun Wang

wangyilunrl@163.com;

wangyilunhenau@126.com

Specialty section:

This article was submitted to

Plant Nutrition,

a section of the journal

Frontiers in Plant Science

Received: 25 March 2020

Accepted: 12 May 2020

Published: 26 June 2020

Citation:

Li L, Lin D, Wang J, Yang L and Wang Y (2020) Multivariate Analysis Models Based on Full Spectra Range

and Effective Wavelengths Using Different Transformation Techniques for Rapid Estimation of Leaf Nitrogen

Concentration in Winter Wheat.

Front. Plant Sci. 11:755.

doi: 10.3389/fp/s.2020.00755

\section{Multivariate Analysis Models Based on Full Spectra Range and Effective Wavelengths Using Different Transformation Techniques for Rapid Estimation of Leaf Nitrogen Concentration in Winter Wheat}

\author{
Lantao Li', Di Lin ${ }^{2}$, Jin Wang ${ }^{3}$, Liu Yang ${ }^{2}$ and Yilun Wang ${ }^{1 *}$
}

${ }^{1}$ College of Resources and Environment, Henan Agricultural University, Zhengzhou, China, ${ }^{2}$ College of Forestry, Henan Agricultural University, Zhengzhou, China, ${ }^{3}$ Soil and Fertilizer Station of Jiaozuo City, Jiaozuo, China

To develop a stable estimation model and identify effective wavelengths that could explain the variations in leaf nitrogen $(\mathrm{N})$ concentration with different $\mathrm{N}$ supplies, growing seasons, ecological locations, growth stages, and wheat cultivars. Four field experiments were performed during two consecutive years (2017-2019) at three sites (Yuanyang, Hebi, and Wenxian) in Henan, China. In situ canopy spectral reflectance data under the aforementioned $\mathrm{N}$ supply conditions were obtained over a range of 400-950 nm (visible and near-infrared region). On the basis of the canopy raw spectral reflectance data and their subsequent transformation by two different techniques, firstderivative reflectance (FDR) and continuum removal $(\mathrm{CR})$, four multivariate regression methods were comparatively analyzed and used to develop predictive models for estimating leaf $N$ concentration: multiple linear regression $(M L R)$, principal component regression (PCR), partial least square (PLS), and support vector machine (SVM). Results showed that leaf $\mathrm{N}$ concentration and canopy reflectance significantly varied with the levels of $\mathrm{N}$ fertilization, and a good correlation was observed for all the spectral techniques. Seven wavelengths with relatively higher $r$ values than the bands of the raw spectra centered at 508, 525, 572, 709, 780, 876, and $925 \mathrm{~nm}$ were specified using the FDR technique. Based on the full wavelengths, the FDR-SVM model exhibited a good performance for leaf $\mathrm{N}$ concentration estimation, with coefficients of determination $\left(r^{2}\right.$ val $)$ for the validation datasets and corresponding relative percent deviations (RPD val $)$ values of 0.842 and 2.383, respectively. However, the FDR-PLS yielded a more accurate assessment of the leaf $\mathrm{N}$ concentration than did the other methods, with $r^{2}$ val and $R P D_{\text {val }}$ values of 0.857 and 2.535 , respectively. The variable importance in projection (VIP) scores from the FDR-PLS with the all canopy spectral region were used to screen the effective wavelengths of the spectral data. Therefore, six effective wavelengths centered at 525, 573, 710, 780, 875, and $924 \mathrm{~nm}$ were identified for leaf $\mathrm{N}$ concentration estimation. The SVM regression method with the effective wavelengths 
showed excellent performance for leaf $\mathrm{N}$ concentration estimation with $r^{2}$ val $=0.823$ and $\mathrm{RPD}_{\text {val }}=2.280$. These results demonstrated that the in situ canopy spectral technique is promising for the estimation of leaf $\mathrm{N}$ concentration in winter wheat based on the FDR-PLS regression model and the effective wavelengths identified.

Keywords: precision nitrogen management, spectral analysis, estimation model, first derivative reflectance, partial least square regression

\section{INTRODUCTION}

Nitrogen $(\mathrm{N})$ is an essential element of pigments as well as proteins associated with crop $\mathrm{N}$ status, and $\mathrm{N}$ is important in terms of plant vigor, yield formation, and grain quality (Din et al., 2018). Precise $\mathrm{N}$ management and accurate estimation of crop $\mathrm{N}$ status are the most common problems in modern agricultural systems not only for economic reasons but also for minimizing the atmospheric, soil, and water pollution associated with excessive N supply (Zhao et al., 2016; Din et al., 2018). Currently, several techniques for the non-destructive estimation of crop $\mathrm{N}$ have been proposed, including leaf color charts, SPAD502, Dualex 4, and CCM-2000 (Schächtl et al., 2005; Din et al., 2018; Zhao et al., 2018). However, all these instruments center on the local test of the leaves and are not practical for application across large fields. Moreover, the techniques actually rely on the absorption of crop chlorophyll and carotenoid instead of $\mathrm{N}$. Several elements, such as leaf thickness, leaf specific mass, the leaf position, the areas from which leaves are measured (Daughtry et al., 2000; Muñoz-Huerta et al., 2013), crop growth, cultivar, and solar radiation (Tahir Ata-Ul-Karim et al., 2016; Din et al., 2018), can influence the results. To overcome these problems, canopy spectral remote sensing (CSRS) has emerged and is recommended as an alternative effective and non-destructive technique for rapidly estimating crop $\mathrm{N}$ status (Yao et al., 2015; Prey and Schmidhalter, 2019).

Canopy spectral remote sensing is a promising approach for the accurate and real-time estimation of crop $\mathrm{N}$ status and other growth variables over large areas (Ecarnot et al., 2013; Feng et al., 2015). CSRS analyses may be performed with field-based spectral radiometers such as the ASD FieldSpec Handheld 2, which can generate a high resolution $(<5 \mathrm{~nm})$ and continuous spectrum at each pixel that is influenced by $\mathrm{N}$ compounds, chlorophyll status, and crop structures; therefore, it provides an effective method for assessing leaf $\mathrm{N}$ concentration at whole canopy scales (Gómez-Casero et al., 2010; Yao et al., 2010; Feng et al., 2015). However, the canopy raw spectra are, however, influenced by the solar radiant flux, crop structure characteristics (e.g., biomass, leaf area index, blade incidence, and plant height), and soil background conditions (Feng et al., 2014; Mahajan et al., 2014). Thus, identifying effective wavelengths for rapidly estimating crop leaf $\mathrm{N}$ concentration has become an extremely important topic in canopy spectral studies. Several canopy spectral transformation techniques, such as first-derivative reflectance (FDR) (Ihuoma and Madramootoo, 2019; Wen et al., 2019) and continuum removal (CR) (Tian et al., 2017; Tan et al., 2019), have been used to improve the signal-to-noise ratio, minimize the impact of atmospheric noise, and enhance weak spectral information of remote monitoring of leaf $\mathrm{N}$ concentration in crops. Experimental investigations have shown that the FDR technique can resolve overlapping absorption phenomena and can minimize the influences of soil or atmospheric background noise (Hruschka, 1987; Miphokasap et al., 2012). Moreover, the CR technique can smooth the spectra, eliminate signal errors caused by the instruments themselves, and suppress the noise within spectral data (Mutanga et al., 2005; Summers et al., 2009; Tan et al., 2019).

On the basis of nearly contiguous spectral wavelengths, overfitting, redundancy, and multicollinearity problems might occur during the modeling of the canopy raw spectra and their subsequent transformation (e.g., via FDR or CR). Multivariable statistical regression methods such as multiple linear regression (MLR), principal component regression_PCR), and partial least square (PLS) analysis were used to reduce multicollinearity and establish a quantitative monitoring model for estimating leaf $\mathrm{N}$ concentration (Hansen and Schjoerring, 2003; Wang et al., 2011; Thorp et al., 2017). Rather than using individual wavelengths for the construction of vegetation indices, the aforementioned approaches incorporate all wavelength data into models for the estimation of plant physiological and biochemical properties (Thorp et al., 2017). For example, MLR is the linear combination of the full-range spectral reflectance and is also the most widely used method for rapidly estimating crop leaf $\mathrm{N}$ concentration using spectral measurements (Huang et al., 2004; Wang et al., 2011). The PCR is a linear regression that first decomposes the spectra into a suite of PCs that offers the maximum variation of the spectra with the aim of optimizing the estimative capacity of the model; it then regresses the PCs against the response variable (Cho et al., 2007; Foster et al., 2016). PLS is closely related to PCR. The difference between PCR and PLS is that while the former uses only the independent variables (e.g., spectral wavelengths) to construct new PCs, the PLS uses both the independent and dependent variables (e.g., leaf $\mathrm{N}$ concentration) that will play the role of explanatory variables to construct PCs. Moreover, the PLS method can reduce the high dimensional and collinear spectral reflectance data to a small quantity of latent variables and effectively eliminate or minimize the overfitting problem (Foster et al., 2016). However, MLR, PCR, and PLS were initially selected for laboratory spectroscopy but are now increasingly used for analyzing CSRS data of maize (Weber et al., 2012; Kawamura et al., 2018), rice (Inoue et al., 2012; Li F. et al., 2014; Li X. C. et al., 2014), and grasslands (Kawamura et al., 2010). Previous studies showed that the selection of effective wavelengths can refine the predictive ability 
of the standard full spectrum by optimizing important effective wavelengths; therefore, several effective wavelength selection methods such as MLR, PCR, and PLS have been developed (Bolster et al., 1996; Yao et al., 2015; Kawamura et al., 2018). Nonetheless, only a limited number of studies made an attempt to evaluate the aforementioned effective wavelength selection methods in combination with spectral transformation techniques (CR and FDR) for a comparative and comprehensive estimation of leaf $\mathrm{N}$ concentration of winter wheat. Moreover, limited previous research, along with its recommended algorithms and spectral indices, has been conducted to estimate the leaf $\mathrm{N}$ concentration in the same ecological locations (Montes et al., 2011; Cao et al., 2017; Zhao et al., 2018; Bruning et al., 2019), neglecting the problem of unsynchronized winter wheat growth stages under different conditions. Therefore, further work is needed to systematically analyze the performance of multiple methods for predicting leaf $\mathrm{N}$ concentration in winter wheat under different ecological areas, unsynchronized growth stages, cultivars, and $\mathrm{N}$ supply.

The specific objectives of this study were to (1) study the relationship between winter wheat leaf $\mathrm{N}$ concentration and the in situ canopy raw spectra and the transformation techniques from field spectral data; (2) compare the reliability and performance of the applied multivariate regression methods based on the raw and the transformed (FDR, CR) spectra for the estimation of leaf $\mathrm{N}$ concentration; (3) determine the optimal method with highest robustness and accuracy and lowest complexity that can rapidly estimate the leaf $\mathrm{N}$ concentration of winter wheat; and (4) determine the sensitivity of the effective wavelengths by using the identified monitoring method and construction of an estimation model of wheat leaf $\mathrm{N}$ concentration.

\section{MATERIALS AND METHODS}

\section{Experimental Design}

Four experiments on wheat were carried out across two growing seasons, with one field located in Yuanyang County $\left(35^{\circ} 6^{\prime} \mathrm{N}\right.$, $\left.113^{\circ} 56^{\prime} \mathrm{E}\right)$, two in Hebi city $\left(35^{\circ} 40^{\prime} \mathrm{N}, 114^{\circ} 17^{\prime} \mathrm{E}\right)$, and one in Wenxian County $\left(34^{\circ} 57^{\prime} \mathrm{N}, 112^{\circ} 59^{\prime} \mathrm{E}\right)$ in Henan Province, North China (Figure 1A). The following variables were included in the study of hexaploid winter wheat: year, ecosystem, cultivar, $\mathrm{N}$ application rate, and sampling date. A randomized complete block design including all treatments in the field experiments was applied, with three replications (Supplementary Table S1 and Figures 1B,C). For all the treatments, phosphorus (P) and potassium $(\mathrm{K})$ nutrition were applied. The recommended $\mathrm{P}$ and $\mathrm{K}$ fertilizer rates were $120 \mathrm{~kg} \mathrm{ha}^{-1}$ (as superphosphate, $12 \% \mathrm{P}_{2} \mathrm{O}_{5}$ ) and $90 \mathrm{~kg} \mathrm{ha}^{-1} \mathrm{~K}_{2} \mathrm{O}$ (as potassium chloride, 60\% $\mathrm{K}_{2} \mathrm{O}$ ). Moreover, the detailed information of $\mathrm{N}$ supply (as controlled-release urea, 44\% N) is shown in Supplementary Table S1. All nutrient resources were applied as a basal fertilizer prior to sowing. Other winter wheat management practices, such as the use of herbicides and disease and pest control followed the local standard practices during the two growing seasons.

\section{Sampling and Measurement Spectral Measurements}

In this study, all the in situ canopy reflectance spectra were obtained with an ASD FieldSpec Handheld 2 passive spectroradiometer (ASD Inc., Boulder, CO, United States) at nadir from a height of approximately $1.0 \mathrm{~m}$ above the winter wheat canopy under sunny conditions between 11:00 and 14:00 (Figure 1D). To reduce the influence of atmospheric and field conditions, the winter wheat canopy spectral reflectance was measured at six sites in each plot, and 60 scans served as the mean canopy spectrum for each plot. A $30 \times 30-\mathrm{cm} \mathrm{BaSO}_{4}$ calibration Spectralon $^{\circledR}$ panel (Spectralon ${ }^{\circledR}$, Labsphere, Inc., North Sutton, NH, United States) was applied to calibrate the reflectance and radiance before and after taking a measurement. Wavelengths below 400 and above $900 \mathrm{~nm}$ were excluded due to the low signal. Therefore, the canopy reflectance data were resampled within the range of 400-900 $\mathrm{nm}$.

\section{Leaf Nitrogen Concentration}

After each measurement of in situ canopy spectral reflectance, four areas of $0.30 \mathrm{~m}^{2}(60 \mathrm{~cm}$ long $\times 50 \mathrm{~cm}$ wide; the spacing interval between the two rows was $20 \mathrm{~cm}$ ) of winter wheat plants from each plot were immediately selected to determine the leaf $\mathrm{N}$ concentration (\%) values by the $\mathrm{H}_{2} \mathrm{SO}_{4}-\mathrm{H}_{2} \mathrm{O}_{2}$ method (Thomas et al., 1967). The leaf $\mathrm{N}$ concentration was measured via a flow injection auto-analyzer (AA3, Bran and Luebbe, Norderstedt, Germany).

\section{Transformation Techniques of Winter Wheat in situ Canopy Spectra}

To smooth the spectra, the frequently used Savitzky-Golay filter was applied, and a second-order polynomial with a window size of five spectral wavelengths was added to eliminate signal noise (Gholizadeh et al., 2015). Afterward, two spectral transformation techniques, FDR and CR, were compared to identify the best techniques for the rapid estimation of the leaf $\mathrm{N}$ concentration from the raw reflectance spectra (Curran et al., 2001; Sims and Gamon, 2002).

\section{First-Derivative Reflectance}

First-Derivative Reflectance spectral transformation technique was applied to reduce the impacts of multiple scattering of radiation (Ihuoma and Madramootoo, 2019). The FDR formula is as follows (Miphokasap et al., 2012):

$$
\operatorname{FDR}\left(\lambda_{\mathrm{i}}=\frac{\left[\mathrm{R}\left(\lambda_{i+1}\right)-\mathrm{R}\left(\lambda_{\mathrm{i}-1}\right)\right]}{2 \Delta \lambda}\right.
$$

Where $\mathrm{R}\left(\lambda_{i+1}\right)$ and $\mathrm{R}\left(\lambda_{i-1}\right)$ are the reflectance values at $\mathrm{i}+1$ and $\mathrm{i}-1$, respectively; and $\Delta \lambda$ is the wavelength increment.

\section{Continuum Removal}

The CR spectral transformation technique was also used to estimate the leaf $\mathrm{N}$ concentration. The continuum line is a convex hull to connect the local maxima of a spectrum (Figure 2). The method was used to assess crop biochemicals with dried plant leaves (Curran et al., 2001), and to the best of our knowledge, 

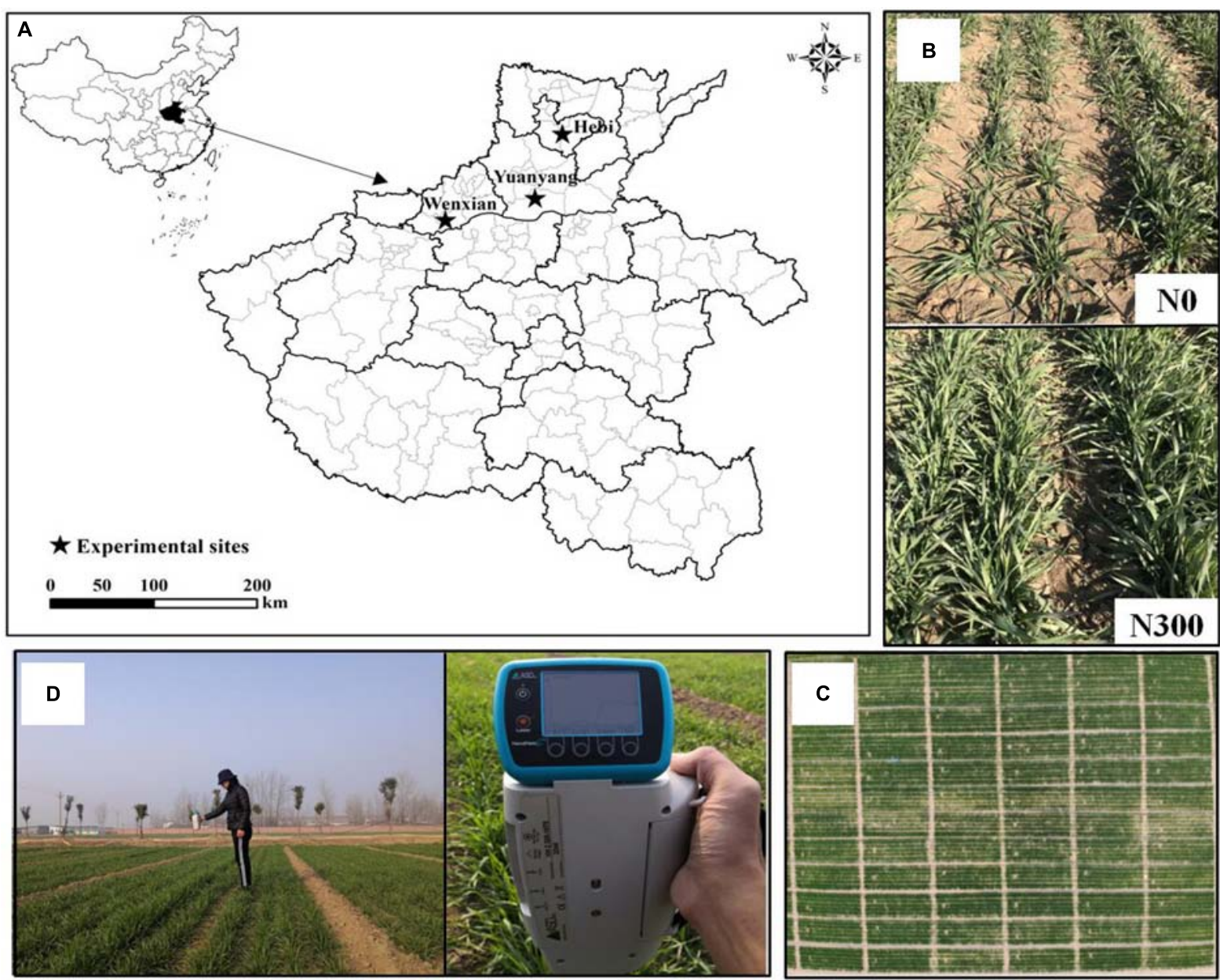

FIGURE 1 | Sites (A), close-up view (B) of the field experiments, aerial view of the N supply plots (C), and measurements of winter wheat canopy spectral reflectance (D).

studies that have extended this technique to in situ canopy spectra under field conditions combined with the quantification of leaf $\mathrm{N}$ concentration in winter wheat are relatively rare (Li et al., 2019).

\section{Data Analysis}

Four different multivariate regression methods were comparatively analyzed and used to estimate the winter wheat $\mathrm{N}$ status at the canopy levels: MLR, PCR, PLS, and support vector machine (SVM).

\section{Multiple Linear Regression Analysis}

Multiple linear regression is a common approach used to calibrate the relationship between multiple independent variables and a dependent variable, which was successfully used for the evaluation of in situ canopy spectra and involved stretching the results of a simple linear regression analysis from a single dimension into multiple dimensions (Bruning et al., 2019).

\section{Principal Component Regression Analysis}

Principal component regression is based on principal component analysis and is also a widely adopted method for dimensionality reduction of spectral data. The optimal number of components to contain in the model was identified by the number of components that had the lowest root mean square error of cross-validation (RMSECV). A 20-fold leave-one-out cross-validation procedure was applied for validating the PCR models to avoid overfitting or underfitting.

\section{Partial Least Square Analysis}

Partial least square is a powerful method that can be used to reduce the in situ reflectance data effectively into a few latent variables with information content and thus maximize the covariance between the spectra and leaf $\mathrm{N}$ concentration. The optimal number of latent variables (ONLVs) of the PLS was the same as that of the PCR and was confirmed based on the lowest RMSECV using the leave-one-out method. In addition, reflectance spectra obtained in this study contained 551 


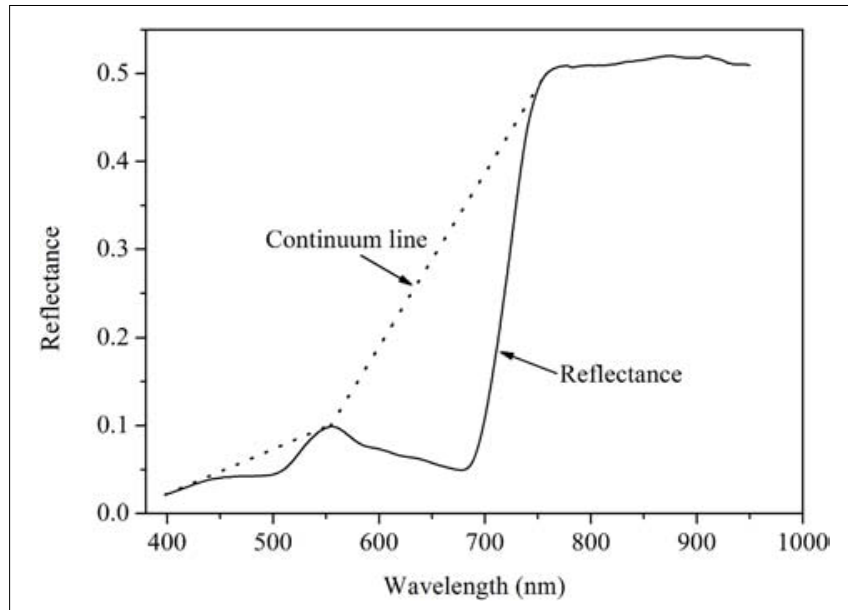

FIGURE 2 | Schematic diagram of the continuum removal technique on the winter wheat canopy.

bands in the range of 400-950 $\mathrm{nm}$. The variable importance in projection (VIP) scores resulting from the PLS were applied to select the effective wavelengths for rapidly estimating the leaf $\mathrm{N}$ concentration. The threshold score of a VIP is 1.0; therefore, a higher VIP score indicates that the wavelength is more important to estimate the leaf $\mathrm{N}$ concentration, while the wavelength having a lower VIP score has less impact on the estimation (Word et al., 2001).

\section{Support Vector Machine Analysis}

In this study, the Gaussian radial basis function (RBF) kernel was used for the SVM technique, and the detailed introduction of the SVM regression model is reported by Schölkopf et al. (2000) and Bishop (2006).

\section{Model Calibration and Validation}

The data function from the four field experiments is shown in Supplementary Table S1. Correlation analysis between the in situ reflectance spectra and leaf $\mathrm{N}$ concentration was performed using the SAS 8.0 (SAS Institute, Cary, NC, United States). The MLR, PCR, PLS, and SVM methods were analyzed using MATLAB 2019a (MathWorks, Natick, MA, United States). The performance of all the regression models was evaluated by the coefficient of determination $\left(r^{2}\right)$, root mean square error (RMSE), and relative percent deviation (RPD) in both the calibration and validation datasets. Detailed information concerning the $r^{2}$ and RPD values of the regression methods is shown in Table $\mathbf{1}$ (Chang et al., 2001).

\section{RESULTS}

\section{Leaf Nitrogen Concentration in Winter Wheat}

Table 2 shows the results of the descriptive analyses of the leaf $\mathrm{N}$ concentration in the calibration, validation, and combined datasets. In the combined datasets, the
TABLE 1 | Classification of the performance of the regression methods in terms of $r^{2}$ and RPD values.

\begin{tabular}{lrcc}
\hline Standards & \multicolumn{3}{c}{ Model performance } \\
\cline { 2 - 4 } & Unacceptable & Acceptable & Excellent \\
\hline$r^{2}$ & $<0.50$ & $0.75-0.50$ & $>0.75$ \\
RPD & $<1.40$ & $2.00-1.40$ & $>2.00$ \\
\hline
\end{tabular}

$R P D$, relative percent deviation.

treatments ( $\mathrm{N}$ rates, ecological sites, and growing seasons and stages) generated a wide range of leaf $\mathrm{N}$ concentration (1.06-6.16\%). Among the datasets, compared with those of validation datasets, the mean and range of the calibration datasets were greater, showing that the classification of the data is appropriate.

\section{Variability of the in situ Spectra Obtained at Various Nitrogen Supplies}

The spectral characteristics of canopy reflectance were significantly different under the different $\mathrm{N}$ treatments but exhibited similar patterns in both the calibration and validation datasets (Figure 3). In the visible spectral region (400-710 nm), the in situ canopy reflectance was higher at low $\mathrm{N}$ supply, whereas in the near-infrared spectral region $(70-950 \mathrm{~nm})$, the canopy reflectance tended to decrease with decreasing $\mathrm{N}$ rates. In addition, reflectance in the near-infrared region led to greater variability compared with that in the visible region, the radiation of which chlorophyll absorbs. The results show that radiation in the near-infrared region was responsive to the different $\mathrm{N}$ supply during different growth stages but tended to saturate at high $\mathrm{N}$ supply.

\section{Correlation of the Leaf Nitrogen Concentration With In situ Canopy Spectra for the Calibration Datasets}

To clarify the relationships of the canopy raw spectra and their subsequent transformation (via the FDR and CR techniques) with the winter wheat leaf $\mathrm{N}$ concentration, correlation analysis was applied to 551 spectral bands from 400 to $950 \mathrm{~nm}$ for the calibration datasets (Figure 4). First, a negative correlation was detected for the visible wavelengths, with the lowest $r$ in the 525-570 $\mathrm{nm}$ range $(r<0.60, n=165)$, whereas a positive correlation was found in the near-infrared region, with the greatest $r$ value in the $720-745 \mathrm{~nm}$ region $(r>0.80$, $n=165$ ) for the raw spectra (Figure 4A). The FDR spectra showed a correlations throughout the full wavelength region (400-950 $\mathrm{nm}$ ) that was stronger than the region of the raw spectra and exhibited more prominent valleys and peaks, for example, at 508, 525, 572, 709, 780, 876, and $925 \mathrm{~nm}$, etc., (Figure 4B). Moreover, the leaf $\mathrm{N}$ concentrations exhibited a weak negative correlation with the CR spectra in the ultraviolet wavelength region (400-420 nm) and a strong positive relationship in the visible near-infrared wavelength region (420-950 $\mathrm{nm}$ ). The average $r$ values in the ultraviolet, 
TABLE 2 | Statistics of winter wheat leaf nitrogen concentration for the calibration and validation datasets.

\begin{tabular}{lccccc}
\hline Datasets & Number of samples & Mean (\%) & Maximum (\%) & Minimum (\%) & SD \\
\hline Calibration datasets & 165 & 3.90 & 6.16 & 1.06 & 1.21 \\
Validation datasets & 150 & 3.70 & 6.02 & 1.12 & 1.27 \\
All datasets & 315 & 3.80 & 6.16 & 1.06 & 34.32 \\
\hline
\end{tabular}

SD, standard deviation; CV (\%), coefficient of variation.
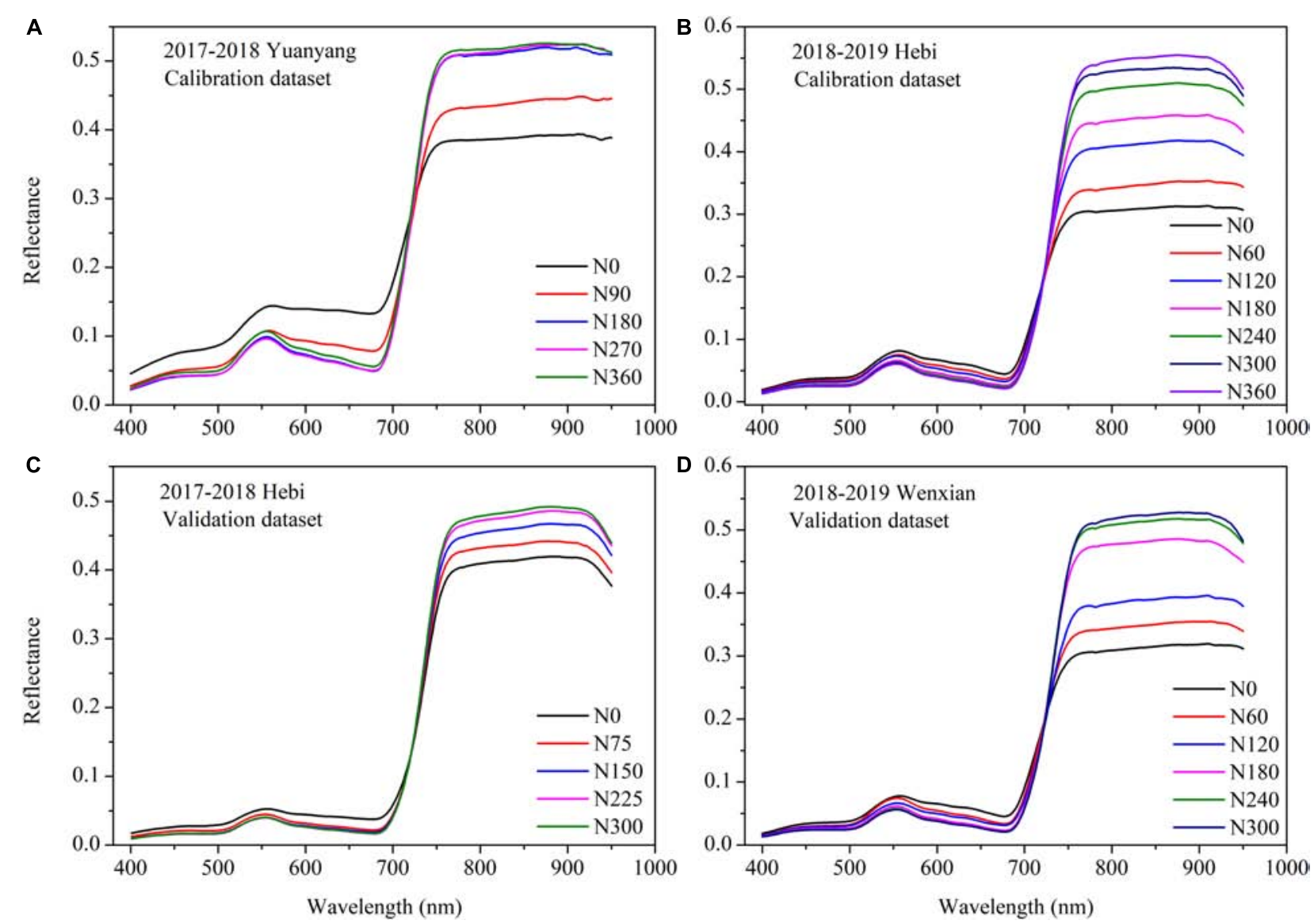

FIGURE 3 | Effect of nitrogen (N) status on the in situ canopy spectral reflectance of winter wheat for the calibration (A,B) and validation (C,D) datasets.

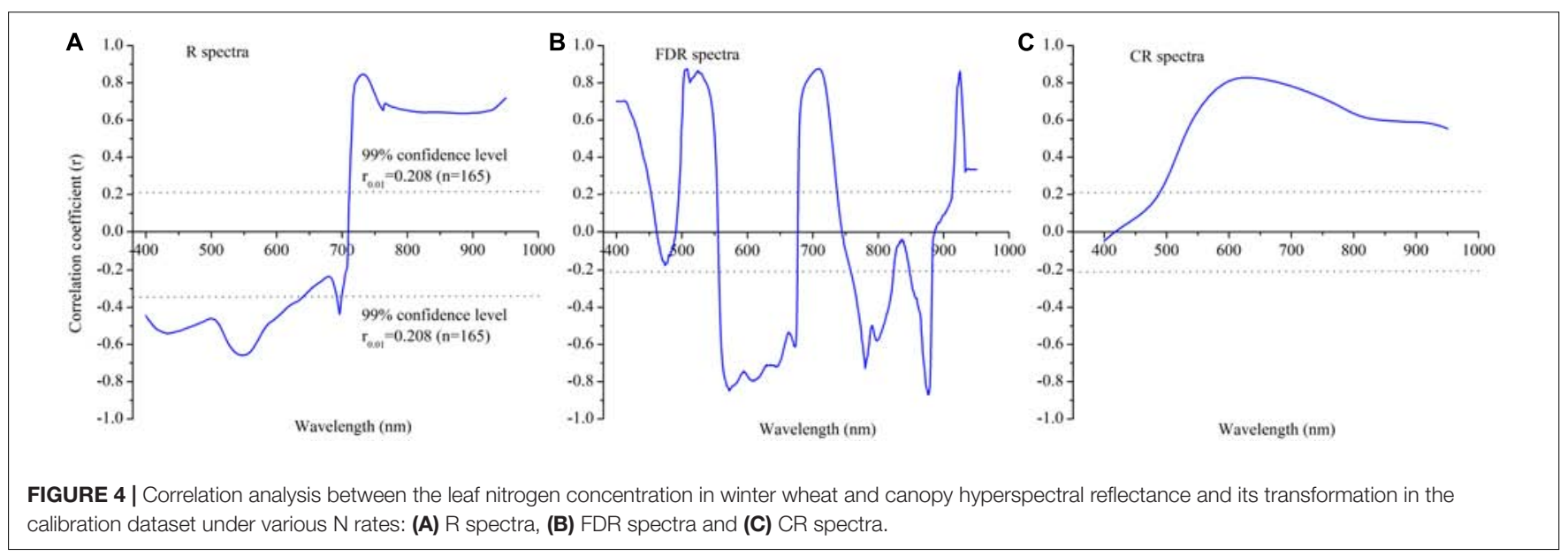


visible, and near-infrared regions were $-0.021,0.551$, and 0.636 , respectively (Figure $4 \mathrm{C}$ ).

\section{Accuracy of Leaf Nitrogen Concentration Estimation With the Multiple Linear Regression, Principal Component Regression, Partial Least Square, and Support Vector Machine}

The robustness and accuracy of the four regression methods for leaf $\mathrm{N}$ concentration estimation using the statistical indicators $r_{c a l / v a l}^{2}, \mathrm{RMSE}_{\text {cal } / v a l}$, and $\mathrm{RPD}_{\text {cal /val }}$ based on different spectral transformation techniques (raw, FDR and CR spectra) were evaluated and compared (Table 3). The FDR based on the PLS analysis generally yielded a measurement accuracy $\left(r_{\text {cal }}^{2}=0.886\right.$, $\left.\mathrm{RPD}_{\text {cal }}=2.973 ; r_{\text {val }}^{2}=0.857, \mathrm{RPD}_{\text {val }}=2.535\right)$ that was greater than that of the other three methods and models. Moreover, the second most important technique for leaf $\mathrm{N}$ concentration estimation after the FDR-PLS was FDR-SVM, which yielded relatively low $r_{\text {cal }}^{2}$ val (1.96 and $1.78 \%$, respectively) and $\mathrm{RPD}_{\text {cal } / v a l}$ (3.69 and 6.38\%, respectively) values in the calibration and validation datasets, respectively. The poorest performance was acquired using the FDR-MLR model (Table 3), with an $r^{2}$ cal of $0.784, \mathrm{RPD}_{\text {cal }}$ of $2.086, r_{\text {val }}^{2}$ of 0.746 , and $\mathrm{RPD}_{\text {val }}$ of 1.584 , respectively. The aforementioned results indicate that the FDRPLS model estimated the leaf $\mathrm{N}$ concentration the best and was identified as the preferred model for use in subsequent analyses.

\section{Effective Wavelength Identification Number of Latent Variables and Cross-Validation}

In this study, the ONLVs was first determined according to the lowest value of the RMSECV (Figure 5A) via the leave-one-out method based on the FDR-PLS model (Figure 5B). To identify the ONLVs, the calibration datasets were applied to investigate how well the model with a different number of latent variables fit the data. As shown in Figure $\mathbf{5 A}$, when the number of latent variables increased, the RMSECV value of the FDR-PLS model tended to decrease. However, the presence of inadequate latent variables led to underfitting, showing the requirement of a balance between the RMSECV value and the number of latent variables. With this criterion, the ONLVs for the FDR-PLS was 7. Figure 5B shows the accuracy of the cross-validation based on the FDR-PLS for the leaf $\mathrm{N}$ concentration estimation. Compared with those from the best fit technique (FDR) for the PLS method, both the $r^{2}\left(r^{2} \mathrm{CV}=0.868\right)$ and $\mathrm{RPD}\left(\mathrm{RPD}_{\mathrm{CV}}=2.756\right)$ values in the cross-validation were relatively high, indicating that the model was acceptable and that the ONLVs was suitable.

\section{Loading Weights of the First-Derivative Reflectance-Partial Least Square Regression Model}

To first clarify the relative impact of each wavelength, the loading weight value was computed and analyzed on the basis of the FDR-PLS model output (Figure 6). The loading weights showed how the latent variables resulting from the FDR-PLS model were developed from scaled estimators of the in situ reflectance spectra (Figures 5, 6). A relatively high absolute loading weight value indicates that the specific wavelength is crucial for the estimation of the leaf $\mathrm{N}$ concentration of winter wheat. In this study, the first four latent variables elucidated more than $81 \%$ of the canopy spectral reflectance variances and $82 \%$ of the leaf $\mathrm{N}$ concentration variances. The highest absolute loading weight values of each wavelength for rapidly estimating the leaf $\mathrm{N}$ concentration were in the visible (525 and $573 \mathrm{~nm}$ ), red-edge $(710 \mathrm{~nm})$, and nearinfrared wavelengths region $(785,870$, and $930 \mathrm{~nm})$ in the first latent variables of the FDR-PLS model (Figure 6). The selected wavelengths of the second loading weight were also in the visible (525 and $570 \mathrm{~nm}$ ), red-edge (678, and $730 \mathrm{~nm}$ ), and near-infrared wavelengths region $(930 \mathrm{~nm})$, while those of the third and fourth loading weights were nearly the same as those of the first and second loading weights.

TABLE 3 | MLR, PCR, PLS, and SVM for predicting leaf nitrogen concentration in winter wheat based on different spectral transformation techniques.

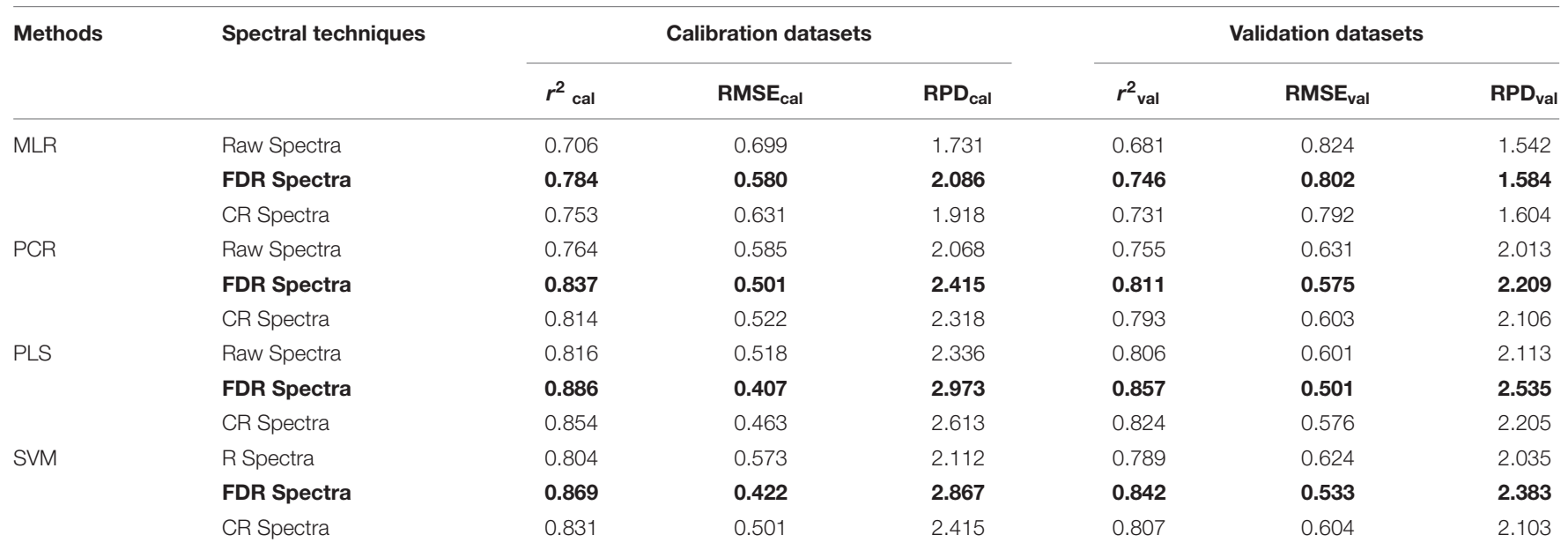

The FDR is highlighted to emphasize the best predictive performance of the four models for predicting leaf nitrogen concentration. MLR, multiple linear regression; PCR, principal component regression; PLS, partial least square; SVM, support vector machine. 

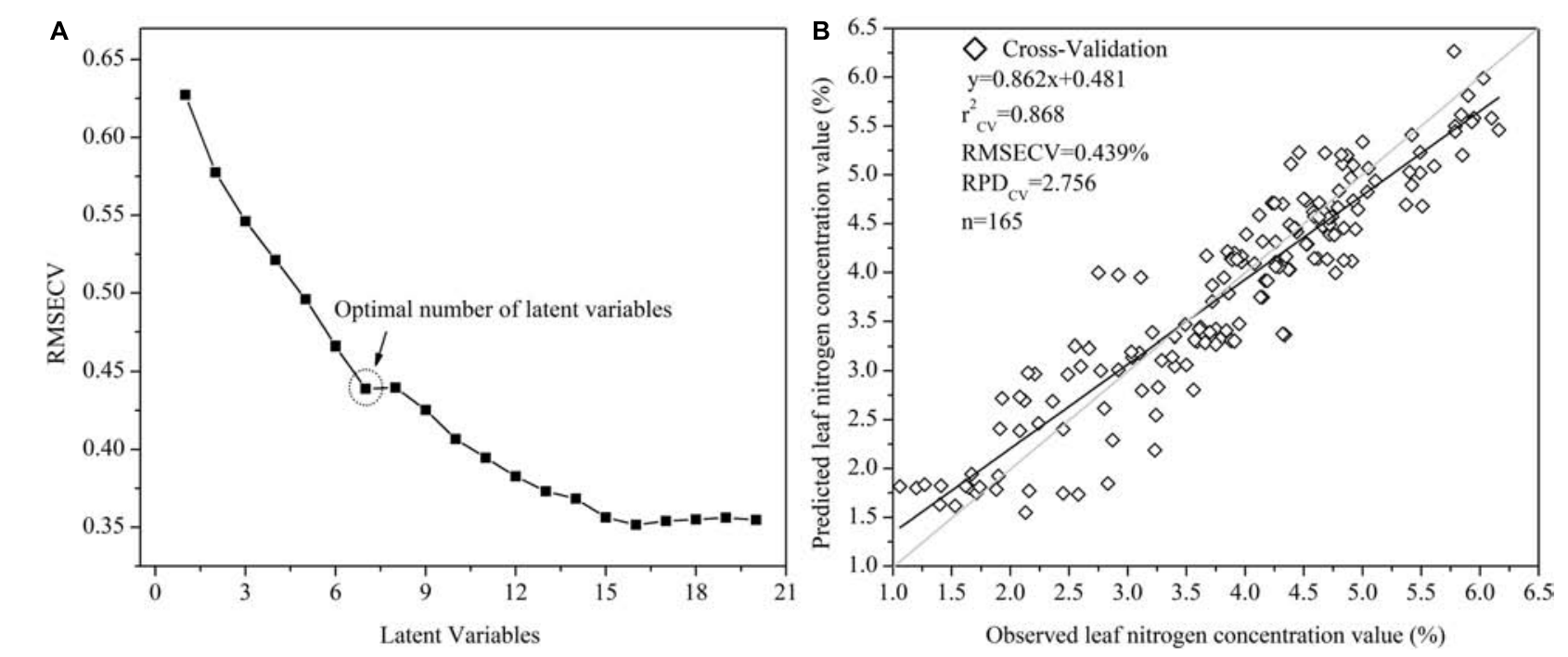

FIGURE $\mathbf{5}$ | Plots with the root mean square error of cross-validation (RMSECV) with the number of latent variables (A) and cross-validation between the observed and predicted leaf nitrogen concentration values (B).

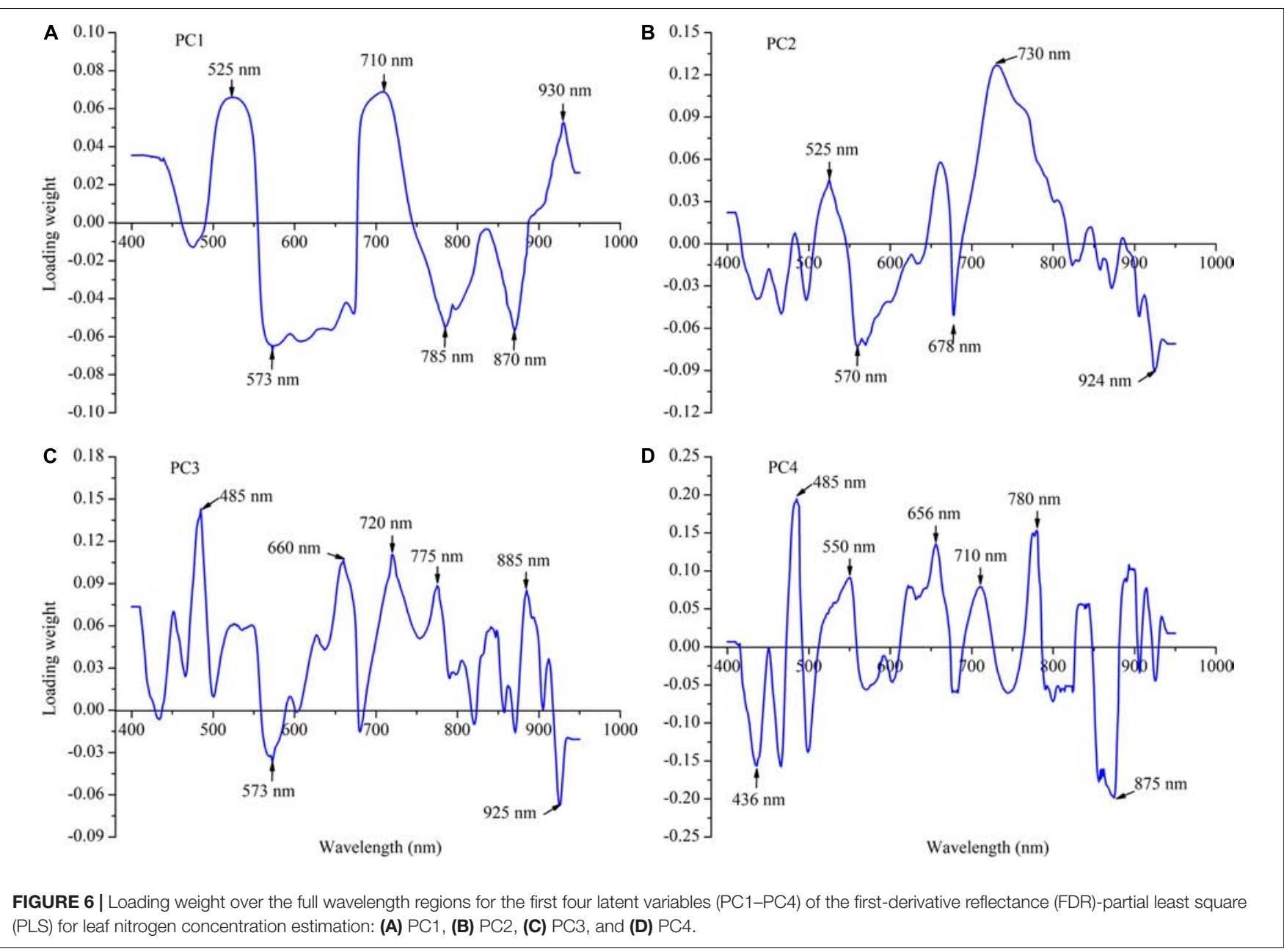




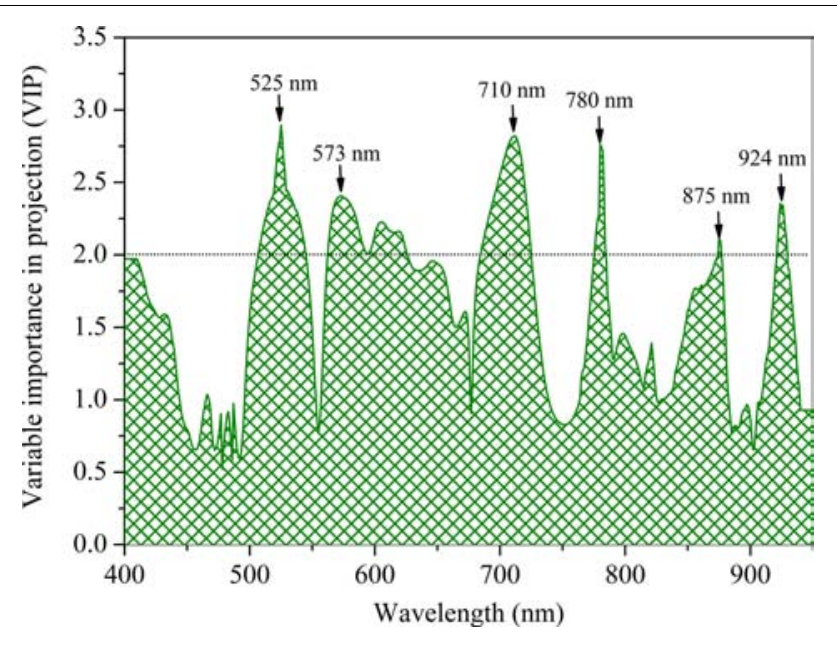

FIGURE 7 | The variable importance in projection (VIP) values over the full wavelength regions for leaf $\mathrm{N}$ concentration estimation.

\section{Effective Wavelength Identification by Variable Importance in Projection Values Based on the First-Derivative Reflectance-Partial Least Square Model}

Owing to the high dimensionality of canopy spectral reflectance data with redundancy between the adjacent wavelengths, it was necessary to select several effective wavelengths that have the most representative information for rapidly estimating the leaf $\mathrm{N}$ concentration of winter wheat. Thus, the VIP scores were applied to select the effective wavelengths for predicting the leaf $\mathrm{N}$ concentration from the full spectral region on the basis of the FDR-PLS model (Figure 7). Generally, a high VIP score shows that the specific wavelength is of vital importance (the threshold value of VIP is 1.0). As shown in Figure 7, given that numerous wavelengths have relatively high VIP scores $(>1.0)$, it was difficult to identify and distinguish the effective wavelengths for rapidly estimating the leaf $\mathrm{N}$ concentration. Therefore, the threshold value of the VIP was set at 2.0 in this study, and six wavelengths were selected as effective, two in the visible (525 and $573 \mathrm{~nm})$, one in the red-edge $(710 \mathrm{~nm})$, and three in the nearinfrared region (780, 875, and $924 \mathrm{~nm}$ ) (Figure 7). Obviously, the identified effective wavelengths based on the VIP for estimating the leaf $\mathrm{N}$ concentration were shown in the same region of PC1 loading weight (Figure 6A).

\section{Multiple Linear Regression, Principal Component Regression, Partial Least Square, and Support Vector Machine Analysis With Effective Wavelengths}

To further illuminate the potential and robustness of the identified effective wavelengths for rapidly estimating the leaf $\mathrm{N}$ concentration of winter wheat, MLR, PCR, PLS, and SVM analyses were developed again based on these effective wavelengths. Figure 8 shows the optimal setting of the metaparameters with the FDR-SVM model. In this study, the optimal combination of epsilon (0.1), $g$ (3.16), and $c$ (100) were calculated based on the RMSECV. Moreover, the results shown in Table 4 indicated that the FDR-PLS model not only exhibited better performance on the calibration datasets, but also offered higher prediction accuracy on the validation datasets. Although $98.91 \%$ (551 vs. 6) of the canopy spectral reflectance variable information was eliminated for the leaf $\mathrm{N}$ concentration estimation, the $r_{\text {val }}^{2}$ (4.6\% for FDR-PLS and 2.3\% for FDR-SVM) and RPD (13.5\% for FDR-PLS and $4.5 \%$ for FDR-SVM) values only showed a slight reduction. The results showed that the identified effective wavelengths and selected revalidated models were promising for rapidly estimating the leaf $\mathrm{N}$ concentration of winter wheat with less computational effort.

\section{DISCUSSION}

Our study demonstrates that CSRS can successfully estimate winter wheat $\mathrm{N}$ status. Canopy reflectance decreased from visible region and increased from near-infrared region as leaf $\mathrm{N}$ concentration increased (Figure 3). Increased $\mathrm{N}$ rates could increase greenness, reflecting a combination of chlorophyll concentration, structural agronomic parameters, and leaf anatomical structure characteristics (Colwell, 1974; Yao et al., 2013; Barankova et al., 2016). The interpretation of the effect of canopy spectral reflectance followed the general assumption that a decrease in greenness or chlorophyll creates higher reflectance in the visible region due to decreased light absorption from a lower chlorophyll concentration (Hinzman et al., 1986; Li et al., $2018 \mathrm{a}, \mathrm{b})$. The opposite effect was found in the near-infrared region; the relative high reflectance spectra observed were due to the canopy and leaf internal scattering and the apparent structure parameters, such as leaf area index and biomass (Colwell, 1974; Hansen and Schjoerring, 2003).

In general, two major approaches have been developed for remote estimation of crop $\mathrm{N}$ status: (i) empirical statistical methods and (ii) physically based retrieval methods such as canopy radiative transfer models (RTMs) (Darvishzadeh et al., 2011; Li et al., 2016). These two methods are mutually complementary (Viña et al., 2011), however, the main disadvantages in using RTM is the ill-posed nature of model inversion (Combal et al., 2002; Houborg et al., 2009), meaning that the inverse solution is not always unique as various combinations of canopy parameters may yield almost similar spectra (Fang et al., 2003). Consequently, the empirical approaches are used more extensively than RTM due to their straightforward mechanisms and efficient computations and have been proposed as better predictors of crop N status (Viña et al., 2011; Delegido et al., 2013). Our study also demonstrates that CSRS can successfully estimate winter wheat $\mathrm{N}$ status using the multivariate statistical approaches. Results indicated that the FDR-PLS was superior to the other models in estimation accuracy (Table 3). These results are consistent with those of Wang et al. (2017) and Nguyen and Lee (2006), showing that the PLS method could reduce the high dimensionality and 


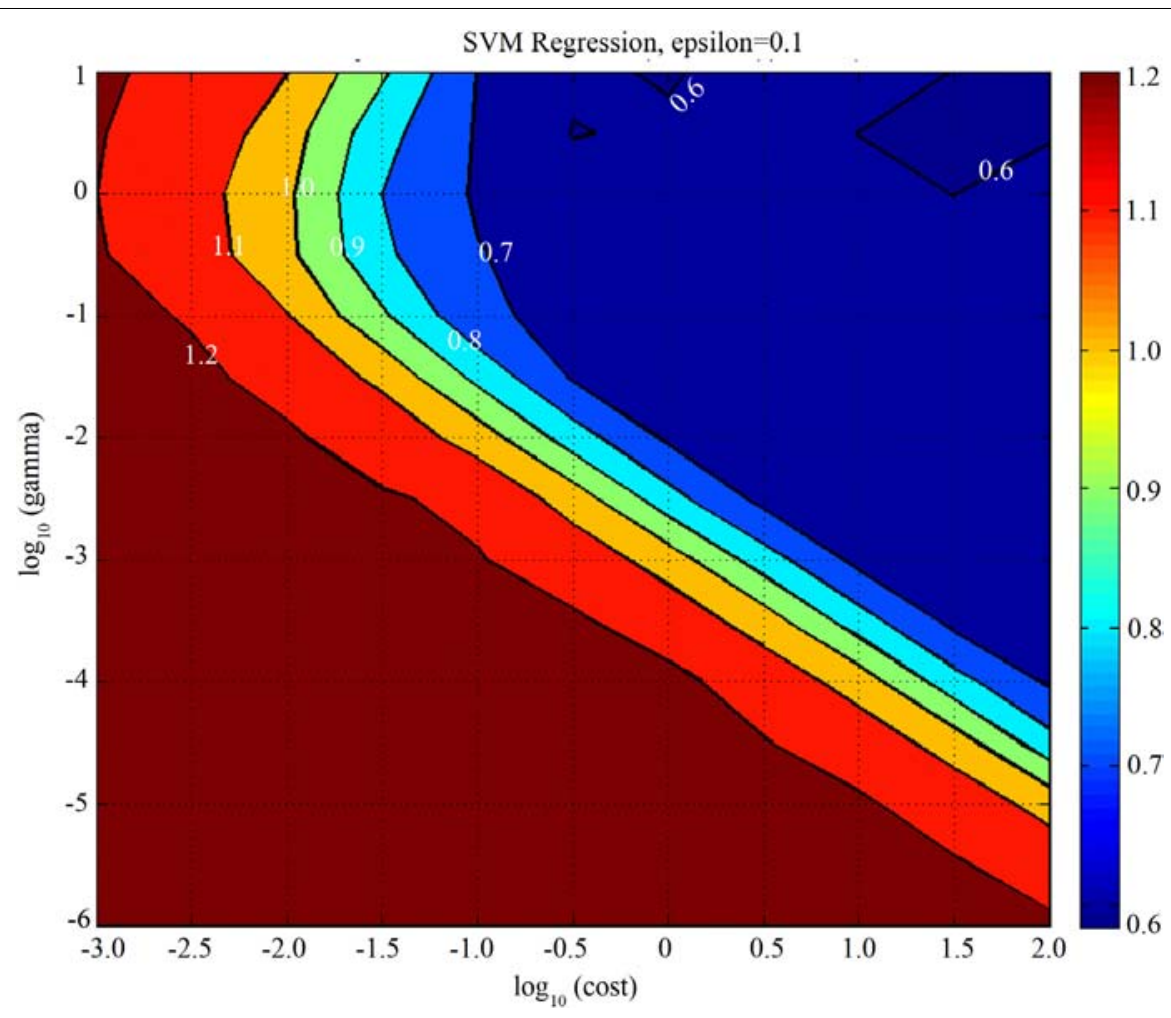

FIGURE 8 | Contour map view of $g, c$, selected by the grid-search method with the first-derivative reflectance (FDR)-support vector machine (SVM) model for leaf nitrogen concentration prediction.

multicollinearity problem of spectral data. The PCR method accounts for only the variance of the explanatory independent variables without considering the internal relationships between the wavelengths and response dependent variables, whereas the PLS accounts for both (Atzberger et al., 2010). Although MLR is the most widely used method for crop biophysical and biochemical estimation using spectral method (Curran et al., 2001; Wang et al., 2011), it might have a collinearity problem (Grossman et al., 1996).

To further rank the estimation models in their predictive power, we calculated several other statistical parameters like the slope (b), intercept (a), and coefficient of deviation (CD) of the linear regressions $(y=a+b \mathrm{x})$ (Supplementary Table S2). The $\mathrm{CD}$ values are all higher than 1.0, indicating that the four models overestimated the predicted values compared to the measured

TABLE 4 | FDR-MLR, FDR-PCR, FDR-PLS, and FDR-SVM analysis for leaf nitrogen concentration prediction of winter wheat using effective wavelengths.

\begin{tabular}{lcccccc}
\hline Models & \multicolumn{3}{c}{ Calibration datasets } & \multicolumn{3}{c}{ Validation datasets } \\
\cline { 2 - 7 } & $\boldsymbol{r}_{\text {cal }}$ & RMSE $_{\text {cal }}$ & RPD $_{\text {cal }}$ & $\boldsymbol{r}^{\mathbf{}_{\text {val }}}$ & RMSE $_{\text {val }}$ & RPD $_{\text {val }}$ \\
\hline FDR-MLR & 0.753 & 0.642 & 1.885 & 0.713 & 0.895 & 1.419 \\
FDR-PCR & 0.808 & 0.581 & 2.083 & 0.784 & 0.615 & 2.065 \\
FDR-PLS & 0.854 & 0.452 & 2.677 & 0.819 & 0.569 & 2.232 \\
FDR-SVM & 0.857 & 0.458 & 2.642 & 0.823 & 0.557 & 2.280
\end{tabular}

data (Müller et al., 2008). The reason for this is presumably the higher range of the calibration datasets than the validation datasets (Table 2), which can be subject to the field conditions uncertainty and as a result lead to considerably overestimation error in the modeling process.

In this study, we mainly discussed the effect of the visible near-infrared range of canopy reflectance on winter wheat $\mathrm{N}$ estimation. For a typical crop canopy, reflectance in the visible spectrum and near-infrared region is often used to estimate leaf $\mathrm{N}$ concentration indirectly due to the strong positive correlation with leaf chlorophyll content and pronounced sensitivity to canopy structures (Kokaly, 2001; Gitelson et al., 2005; Li et al., 2019). However, the sensitive absorption wavelength of $\mathrm{N}$ lies in short-wave-infrared, which is easily obscured by water-vapor absorption characteristics (Curran, 1989; Fourty et al., 1996; Feng et al., 2008). Moreover, the spectral sensing information obtained in this study was from field-based spectral radiometers; research on aerial-based hyperspectral imagery for crop $\mathrm{N}$ status estimation is an important tendency in precision agriculture (Nigon et al., 2015; Bruning et al., 2019). Unlike conventional field-based spectrometers that only collect spectral information for a single point, a hyperspectral imaging system can obtain images of the whole target for each wavelength recorded ( $\mathrm{Wu}$ and Sun, 2013). Future work should evaluate these results for diverse species, under different environmental conditions, and using not only in situ measurements but also airborne and satellite data. 


\section{CONCLUSION}

The overall results from this research showed that winter wheat leaf $\mathrm{N}$ concentration could be assessed with reasonable accuracy from field in situ canopy spectral data. We conclude that: (i) the FDR-PLS regression model was performed better than other model techniques evaluated for leaf $\mathrm{N}$ concentration of winter wheat; (ii) Six bands centered at 525, 573, 710, 780, 875, and $924 \mathrm{~nm}$ were identified as effective wavelengths for leaf $\mathrm{N}$ concentration estimation using the in situ canopy spectra; (iii) An acceptable accuracy with $r^{2}\left(r_{c a l}^{2}=0.857 ; r_{\text {val }}^{2}=0.823\right)$ and $\mathrm{RPD}\left(\mathrm{RPD}_{\text {cal }}=2.642 ; \mathrm{RPD}_{\mathrm{val}}=2.280\right)$ was acquired using the FDR-SVM based on the effective wavelengths.

\section{DATA AVAILABILITY STATEMENT}

All datasets presented in this study are included in the article/Supplementary Material.

\section{AUTHOR CONTRIBUTIONS}

LL designed the study and wrote the manuscript. YW conceptualized the manuscript. DL and LY conducted the field

\section{REFERENCES}

Atzberger, C., Guerif, M., Baret, F., and Werner, W. (2010). Comparative analysis of three chemometric techniques for the spectroradiometric assessment of canopy chlorophyll content in winter wheat. Comput. Electron. Agric. 73, 165-173. doi: 10.1016/j.compag.2010.05.006

Barankova, B., Lazar, D., and Naus, J. (2016). Analysis of the effect of chloroplast arrangement on optical properties of green tobacco leaves. Remote Sens. Environ. 174, 181-196. doi: 10.1016/j.rse.2015.12.011

Bishop, C. M. (2006). Pattern Recognition And Machine Learning. New York, NY: Springer.

Bolster, K. L., Martin, M. E., and Aber, J. D. (1996). Determination of carbon fraction and $\mathrm{N}$ concentration in tree foliage by near infrared reflectance: a comparison of statistical methods. Can. J. Forest Res. 26, 590-600.

Bruning, B., Liu, H. J., Brien, C., Berger, B., Lewis, M., and Garnett, T. (2019). The development of hyperspectral distribution maps to predict the content and distribution of nitrogen and water in wheat (Triticum awstivum). Front. Plant Sci. 10:1380. doi: 10.3389/fpls.2019.01380

Cao, Q., Miao, Y. X., Feng, G. H., Gao, X. W., Liu, B., Liu, Y. Q., et al. (2017). Improving nitrogen use efficiency with minimal environmental risks using an active canopy sensor in a wheat-maize cropping system. Field Crops Res. 214, 365-372.

Chang, C., Laird, D. A., Mausbach, M. J., and Hurburgh, C. R. (2001). Near infrared reflectance spectroscopy: principal components regression analysis of soil properties. Soil Sci. Soc. Am. J. 65, 480-490.

Cho, M. A., Skidmore, A., Corsi, F., Van Wieren, S. E., and Sobhan, I. (2007). Estimation of green grass/ herb biomass from airborne hyperspectral imagery using spectral indices and partial least squares regression. Intern. J. Appl. Earth Observ. Geoinform. 9, 414-424. doi: 10.1016/j.jag.2007.02.001

Colwell, J. E. (1974). Vegetation canopy reflectance. Remote Sens. Environ. 3, 175-183. doi: 10.1016/0034-4257(74)90003-90000

Combal, B., Baret, F., and Weiss, M. (2002). Improving canopy variables estimation from remote sensing data by exploiting ancillary information. Case study on sugar beet canopies. Agronomie 22, 205-215. doi: 10.1051/agro:2002008

Curran, P. J. (1989). Remote sensing of foliar chemistry. Remote Sens. Environ. 30, 271-278. doi: 10.1016/0034-4257(89)90069-90062 experiments. JW contributed the tables and figures. All authors contributed to the article and approved the submitted version.

\section{FUNDING}

This research work was financially supported by the National Key R\&D Program of China (2017YFD0301106) and the special fund for young talents in Henan Agricultural University (30500427).

\section{ACKNOWLEDGMENTS}

We are grateful to the reviewers for their insightful comments, which greatly improved the manuscript.

\section{SUPPLEMENTARY MATERIAL}

The Supplementary Material for this article can be found online at: https://www.frontiersin.org/articles/10.3389/fpls.2020.00755/ full\#supplementary-material

Curran, P. J., Dungan, J. L., and Peterson, D. L. (2001). Estimating the foliar biochemical concentration of leaves with reflectance spectrometry. Testing the Kokaly and Clark methodologies. Remote Sens. Environ. 76, 349-359. doi: 10. 1016/S0034-4257(01)00182-181

Darvishzadeh, R., Atzberger, C., Skidmore, A., and Schlerf, M. (2011). Mapping grassland leaf area index with airborne hyperspectral imagery: a comparison study of statistical approaches and inversion of radiative transfer models. ISPRS J. Photogram. Remote Sens. 66, 894-906. doi: 10.1016/j.isprsjprs.2011. 09.013

Daughtry, C. S. T., Walthall, C. L., Kim, M. S., De Colstoun, E. B., and McMurtrey, J. E. (2000). Estimating corn leaf chlorophyll concentration from leaf and canopy reflectance. Remote Sens. Environ. 74, 229-239. doi: 10.1016/S00344257(00)00113-119

Delegido, J., Verrelst, J., Meza, C. M., Rivera, J. P., Alonso, L., and Moreno, J. (2013). A red edge spectral index for remote sensing estimation of green LAI over agroecosystems. Eur. J. Agron. 46, 42-52. doi: 10.1016/j.eja.2012. 12.001

Din, M., Ming, J., Hussain, S., Ata-Ul-Karim, S. T., Rashid, M., Tahir, M. N., et al. (2018). Estimation of dynamic canopy variables using hyperspectral derived vegetation indices under varying $\mathrm{N}$ rates at diverse phonological stages of rice. Front. Plant Sci. 9:1883. doi: 10.3389/fpls.2018.01883

Ecarnot, M., Compan, F., and Rounmet, P. (2013). Assessing leaf nitrogen content and leaf mass per unit area of wheat in the field throughout plant cycle with a portable spectrometer. Field Crops Res. 140, 44-50. doi: 10.1016/j.fcr.2012.10. 013

Fang, H. L., Liang, S. L., and Kuusk, A. (2003). Retrieving leaf area index using a genetic algorithm with a canopy radiative transfer model. Remote Sens. Environ. 85, 257-270. doi: 10.1016/S0034-4257(03)00005-1

Feng, W., Guo, B. B., Wang, Z. J., He, L., Song, X., Wang, Y. H., et al. (2014). Measuring leaf nitrogen concentration in winter wheat using double-peak spectral reflection remote sensing data. Field Crops Res. 159, 43-52. doi: 10. 1016/j.fcr.2014.01.010

Feng, W., Guo, B. B., Zhang, H. Y., He, L., Zhang, Y. S., Wang, Y. H., et al. (2015) Remote estimation of above ground nitrogen uptake during vegetative growth in winter wheat using hyperspectral red-edge ratio data. Field Crops Res. 180, 197-206. doi: 10.1016/j.fcr.2015.05.020 
Feng, W., Yao, X., Zhu, Y., Tian, Y. C., and Cao, W. X. (2008). Monitoring leaf nitrogen status with hyperspectral reflectance in wheat. Eur. J. Agron. 28, 394-404. doi: 10.1016/j.eja.2007.11.005

Foster, A. J., Kakani, V. G., and Mosali, J. (2016). Estimation of bioenergy crop yield and $\mathrm{N}$ status by hyperspectral canopy reflectance and partial least square regression. Precis. Agric. 17, 1-18.

Fourty, T., Baret, F., Jacquemoud, S., Schmuck, G., and Verdebout, J. (1996). Leaf optical properties with explicit description of its biochemical composition: direct and inverse problems. Remote Sens. Environ. 56, 104-117. doi: 10.1016/ 0034-4257(95)00234-230

Gholizadeh, A., Boruvka, L., Saberioon, M. M., Kozak, J., Vasat, R., and Nemecek, K. (2015). Comparing different data preprocessing methods for monitoring soil heavy metals based on soil spectral features. Soil Water Res. 10, 218-227. doi: 10.17221/113/2015-SWR

Gitelson, A. A., Vina, A., Ciganda, V., Rundquist, D. C., and Arkebauer, T. J. (2005). Remote estimation of canopy chlorophyll content in crops. Geophys. Res. Lett. $32,93-114$.

Gómez-Casero, M. T., Castillejo-González, I. L., García-Ferrer, A., PeñaBarragán, J. M., Jurado-Expósito, M., García-Torres, L., et al. (2010). Spectral discrimination of wild oat and canary grass in wheat fields for less herbicide application. Agron. Sustain. Dev. 30, 689-699. doi: 10.1051/agro/200 9052

Grossman, Y. L., Ustin, S. L., and Jacquemoud, J. (1996). Critique of stepwise multiple linear regression for the extraction of leaf biochemistry information from leaf reflectance data. Remote Sens. Environ. 56, 182-193. doi: 10.1016/ 0034-4257(95)00235-9

Hansen, P. M., and Schjoerring, J. K. (2003). Reflectance measurement of canopy biomass and nitrogen status in wheat crops using normalized difference vegetation indices and partial least squares regression. Remote Sens. Environ. 86, 542-553. doi: 10.1016/S0034-4257(03)00131-137

Hinzman, L. D., Bauer, M. E., and Daughtry, C. S. T. (1986). Effects of nitrogen fertilization on growth and reflectance characteristics of winter wheat. Remote Sens. Environ. 19, 47-61. doi: 10.1016/0034-4257(86)90040-90044

Houborg, R., Anderson, M., and Daughtry, C. (2009). Utility of an image-based canopy reflectance modeling tool for remote estimation of LAI and leaf chlorophyll content at the field scale. Remote Sens. Environ. 113, 259-274. doi: 10.1016/j.rse.2008.09.014

Hruschka, W. R. (1987). "Data analysis: wavelength selection methods," in NearInfrared Technology in the Agricultural and Food Industries, eds P. Williams and K. Norris (St. Paul, MN: American Association of Cereal Chemists, Inc.), 35-53.

Huang, Z., Turner, B. J., Dury, S. J., Wallis, I. R., and Foley, W. J. (2004). Estimating foliage nitrogen concentration from HYMAP data using continuum removal analysis. Remote Sens. Environ. 93, 18-29. doi: 10.1016/j.rse.2004.06.008

Ihuoma, S. O., and Madramootoo, C. A. (2019). Sensitivity of spectral vegetation indices for monitoring water stress in tomato plants. Comput. Electron. Agric. 163:104860. doi: 10.1016/j.compag.2019.104860

Inoue, Y., Sakaiya, E., Zhu, Y., and Takahashi, W. (2012). Diagnostic mapping of canopy nitrogen content in rice based on hyperspectral measurements. Remote Sens. Environ. 126, 210-221. doi: 10.1016/j.rse.2012.08.026

Kawamura, K., Ikeura, H., Phongchanmaixay, S., and Khanthavong, P. (2018). Canopy hyperspectral sensing of paddy fields at the booting stage and PLS regression can assess grain yield. Remote Sens. Environ. 10:81249. doi: 10.3390/ rs10081249

Kawamura, K., Watanabe, N., Sakanoue, S., Lee, H. J., Inoue, Y., and Odagawa, S. (2010). Testing genetic algorithm as a tool to select relevant wavebands from field hyperspectral data for estimating pasture mass and quality in a mixed sown pasture using partial least squares regression. Grassland Sci. 56, 205-216. doi: 10.1111/j.1744-697x.2010.00196.x

Kokaly, R. F. (2001). Investigating a physical basis for spectroscopic estimates of leaf nitrogen concentration. Remote Sens. Environ. 75, 153-161. doi: 10.1016/ S0034-4257(00)00163-162

Li, F., Mistele, B., Hu, Y., Chen, X., and Schmidhalter, U. (2014). Reflectance estimation of canopy nitrogen content in winter wheat using optimised hyperspectral spectral indices and partial least squares regression. Eur. J. Agron. 52, 198-209. doi: 10.1016/j.eja.2013.09.006

Li, X. C., Zhang, Y. J., Bao, Y. S., Luo, J. H., Jin, X. L., Xu, X. G., et al. (2014). Exploring the best hyperspectral features for LAI estimation using partial leaf squares regression. Remote Sens. 6, 6221-6241. doi: 10.3390/rs6076221
Li, F. L., Wang, L., Liu, J., Wang, Y. N., Chang, Q. R., and Li, F. (2019). Evaluation of leaf $\mathrm{N}$ concentration in winter wheat based on discrete wavelet transform analysis. Remote Sens. 11:1331. doi: 10.3390/rs11111331

Li, L. T., Jákli, B., Lu, P. P., Ren, T., Ming, J., Liu, S. S., et al. (2018a). Assessing leaf nitrogen concentration of winter oilseed rape with canopy hyperspectral technique considering a non-uniform vertical nitrogen distribution. Industr. Crops Products 116, 1-14. doi: 10.1016/j.indcrop.2018.02.051

Li, L. T., Wang, S. Q., Ren, T., Wei, Q. Q., Ming, J., Li, J., et al. (2018b). Ability of models with effective wavelengths to monitor nitrogen and phosphorus status of winter oilseed rape leaves using in situ canopy spectroscopy. Field Crops Res. 215, 173-186. doi: 10.1016/j.fcr.2017.10.018

Li, L. T., Ren, T., Ma, Y., Wei, Q. Q., Wang, S. Q., Li, X. K., et al. (2016). Evaluating chlorophyll density in winter oilseed rape (Brassica napus L.) using canopy hyperspectral red-edge parameters. Comput. Electron. Agric. 126, 21-31.

Mahajan, G. R., Sahoo, R. N., Pandey, R. N., Gupta, V. K., and Kumar, D. (2014). Using hyperspectral remote sensing techniques to monitor nitrogen, phosphorus, sulphur and potassium in wheat (Triticum aestivum L.). Precis. Agric. 15, 499-522. doi: 10.1007/s11119-014-9348-9347

Miphokasap, P., Honda, K., Vaiphasa, C., Souris, M., and Nagai, M. (2012). Estimating canopy nitrogen concentration in sugarcane using field imaging spectroscopy. Remote Sens. 4, 1651-1670. doi: 10.3390/rs4061651

Montes, J. M., Technow, F., Dhillon, B. S., Mauch, F., and Melchinger, A. E. (2011). High-throughput non-destructive biomass determination during early plant developmentin maize under field conditions. Field Crops Res. 121, 268-273. doi: 10.1016/j.fcr.2010.12.017

Müller, K., Böttcher, U., Meyer-Schatz, F., and Kage, H. (2008). Analysis of vegetation indices derived from hyperspectral reflection measurements for estimating crop canopy parameters of oilseed rape (Brassica napus L.). Biosyst. Eng. 101, 172-182. doi: 10.1016/j.biosystemseng.2008.07.004

Muñoz-Huerta, R., Guevara-Gonzalez, R. G., Contreras-Medina, L. M., TorresPacheco, I., Prado-Olivarez, J., and Ocampo-Velazquez, R. V. (2013). A review of methods for sensing the nitrogen status in plants: advantages, disadvantages and recent advances. Sensors 13, 10823-10843. doi: 10.3390/s13081 0823

Mutanga, O., Skidmore, A. K., Kumar, L., and Ferwerda, J. (2005). Estimating tropical pasture quality at canopy level using band depth analysis with continuum removal in the visible domain. Intern. J. Remote Sens. 26, 10931108. doi: 10.1080/01431160512331326738

Nguyen, H. T., and Lee, B. W. (2006). Assessment of rice leaf growth and nitrogen status by hyperspectral canopy reflectance and partial least square regression. Eur. J. Agron. 24, 349-356. doi: 10.1016/j.eja.2006.01.001

Nigon, T. J., Mulla, D. J., Rosen, C. J., Cohen, Y., and Alchanatis, V. (2015). Hyperspectral aerial imagery for detecting nitrogen stress in two potato cultivars. Comput. Electron. Agric. 112, 36-46. doi: 10.1016/j.compag.2014.12. 018

Prey, L., and Schmidhalter, U. (2019). Simulation of satellite reflectance data using high-frequency ground based hyperspectral canopy measurements for in-season estimation of grain yield and grain nitrogen status in winter wheat. ISPRS J. Photogram. Remote Sens. 149, 176-187. doi: 10.1016/j.isprsjprs.2019. 01.023

Schächtl, J., Huber, G., Maidl, F. X., Sticksel, E., Schulz, J., and Haschberger, P. (2005). Laser-induced chlorophyll fluorescence measurements for detecting the nitrogen status of wheat (Triticum aestium L.) canopies. Precis. Agric. 6, 143-156. doi: 10.1007/s11119-004-1031-y

Schölkopf, B., Smola, A. J., Williamson, R. C., and Bartlett, P. L. (2000). New support vector algorithms. Neural Comput. 12, 1207-1245. doi: 10.1162/ 089976600300015565

Sims, D. A., and Gamon, J. A. (2002). Relationships between leaf pigment content and spectral reflectance across a wide range of species, leaf structures and developmental stages. Remote Sens. Environ. 81, 337-354. doi: 10.1016/S00344257(02)00010-X

Summers, D., Lewis, M., Ostendorf, B., and Chittleborough, D. (2009). Visible near-infrared reflectance spectroscopy as a predictive indicator of soil properties. Ecol. Indic. 11, 123-131. doi: 10.1016/j.ecolind.2009. 05.001

Tahir Ata-Ul-Karim, S., Liu, X., Lu, Z., Yuan, Z., Zhu, Y., and Cao, W. (2016). Inseason estimation of rice grain yield using critical nitrogen dilution curve. Field Crops Res. 195, 1-8. doi: 10.1016/j.fcr.2016.04.027 
Tan, K., Ma, W. B., Wu, F. Y., and Du, Q. (2019). Random forest-based estimation of heavy metal concentration in agricultural soils with hyperspectral sensor data. Environ. Monitor. Assessm. 191:446. doi: 10.1007/s10661-019-7510-7514

Thomas, R. L., Shearad, R. W., and Moyer, J. R. (1967). Comparison of conventional and automated procedures for nitrogen, phosphorus, and potassium analysis of plant material using a single digestion. Agron. J. 59, 240-243. doi: 10.2134/agronj1967.00021962005900030010x

Thorp, K. R., Wang, G., Bronson, K. F., Badaruddin, M., and Mon, J. (2017). Hyperspectral data mining to identify relevant canopy spectral features for estimating durum wheat growth, nitrogen status, and grain yield. Comput. Electron. Agric. 136, 1-12. doi: 10.1016/j.compag.2017.02.024

Tian, H. Q., Shi, S. D., Wang, H., Li, F., Li, Z., and Alva, A. (2017). Estimating of sugar beet aboveground biomass by band depth optimization of hyperspectral canopy reflectance. J. Indian Soc. Remote Sens. 45, 795-803. doi: 10.1007/ s12524-016-0632-z

Viña, A., Gitelson, A. A., Nguy-Robertson, A. L., and Peng, Y. (2011). Comparison of different vegetation indices for the remote assessment of green leaf area index of crops. Remote Sens. Environ. 115, 3468-3478. doi: 10.1016/j.rse.2011.08.010

Wang, F. M., Huang, J. F., and Lou, Z. H. (2011). A comparison of three methods for estimating leaf area index of paddy rice from optimal hyperspectral bands. Precis. Agric. 12, 439-447. doi: 10.1007/s11119-010-9185-9182

Wang, J., Shen, C. W., Liu, N., Jin, X., Fan, X. S., Dong, C. X., et al. (2017). Nondestructive evaluation of the leaf nitrogen concentration by in-field visible/nearinfrared spectroscopy in pear orchards. Sensors 17:538. doi: 10.3390/s17030538

Weber, V. S., Araus, J. L., Cairns, J. E., Sanchez, C., Melchinger, A. E., and Orsini, E. (2012). Prediction of grain yield using reflectance spectra of canopy and leaves in maize plants grown under different water regimes. Field Crops Res. 128, 82-90. doi: 10.1016/j.fcr.2011.12.016

Wen, P. F., He, J., Ning, F., Wang, R., Zhang, Y. H., and Li, J. (2019). Estimating leaf nitrogen concentration considering unsynchronized maize growth stages with canopy hyperspectral technique. Ecol. Indic. 107:105590. doi: 10.1016/j.ecolind. 2019.105590

Word, S., Sjöström, M., and Eriksson, L. (2001). Pls-regression: a basic tool of chemometrics. Chemometr. Intellig. Lab. Syst. 58, 109-130. doi: 10.1016/S01697439(01)00155-151
Wu, D., and Sun, D. W. (2013). Potential of time series-hyperspectral imaging (TS-HSI) for non-invasive determination of microbial spoilage of salmon flesh. Talanta 111, 39-46. doi: 10.1016/j.talanta.2013.03.041

Yao, X., Huang, Y., Shang, G. Y., Zhou, C., Cheng, T., Tian, Y. C., et al. (2015). Evaluation of six algorithms to monitor wheat leaf nitrogen concentration. Remote Sens. 7, 14939-14966. doi: 10.3390/rs7111 4939

Yao, X., Zhu, Y., Tian, Y. C., Feng, W., and Cao, W. X. (2010). Exploring hyperspectral bands and estimation indices for leaf nitrogen accumulation in wheat. Intern. J. Appl. Earth Observ. Geoinform. 12, 89-100. doi: 10.1016/j.jag. 2009.11.008

Yao, X. F., Yao, X., Tian, Y. C., Ni, J., Liu, X. K., Cao, W. X., et al. (2013). A new method to determine central wavelength and optimal bandwidth for predicting plantnitrogen uptake in winter wheat. J. Integr. Agric. 12, 788-802. doi: 10.1016/S2095-3119(13)60300-60307

Zhao, B., Duan, A., Ata-Ul-karim, S. T., Liu, Z., Chen, Z., Gong, Z., et al. (2018). Exploring new spectral bands and vegetation indices for estimating nitrogen nutrition index of summer maize. Eur. J. Agron. 93, 113-125. doi: 10.1016/j.eja. 2017.12.006

Zhao, B., Liu, Z., Ata-Ul-Karim, S. T., Xiao, J., Liu, Z., Qi, A., et al. (2016). Rapid and non-destructive estimation of the nitrogen nutrition index in winter barley using chlorophyll measurements. Field Crops Res. 185, 59-68. doi: 10.1016/j.fcr. 2015.10.021

Conflict of Interest: The authors declare that the research was conducted in the absence of any commercial or financial relationships that could be construed as a potential conflict of interest.

Copyright (c) $2020 \mathrm{Li}$, Lin, Wang, Yang and Wang. This is an open-access article distributed under the terms of the Creative Commons Attribution License (CC BY). The use, distribution or reproduction in other forums is permitted, provided the original author(s) and the copyright owner(s) are credited and that the original publication in this journal is cited, in accordance with accepted academic practice. No use, distribution or reproduction is permitted which does not comply with these terms. 